\title{
FLUOXETIN CONTAINING PVP-BASED ELECTROSPUN NANOFIBERS
}

\author{
EMŐKE MARGIT RÉDAI ${ }^{*}$, ORSOLYA K KOVÁCS ${ }^{1}$, ZOLTÁN ISTVÁN SZABÓ1, \\ ATTILA L GERGELY ${ }^{2}$, PAULA ANTONOAEA ${ }^{1}$, NICOLETA TODORAN ${ }^{1}$, \\ ROBERT ALEXANDRU VLAD ${ }^{1}$, ADRIANA CIURBA ${ }^{1}$, GABRIELLA DÓNÁTH-NAGY ${ }^{1}$, \\ and EMESE SIPOS ${ }^{1}$
}

",George Emil Palade” University of Medicine, Pharmacy, Science, and Technology of Targu Mures, Romania

${ }^{2}$ Sapientia Hungarian University of Transylvania, Romania

\begin{abstract}
Fluoxetine hydrochloride is a selective serotonin reuptake inhibitor used in the treatment of depression and obsessive-compulsive disorder. The aim of this study is represented by developing fluoxetineloaded polyvinylpyrrolidone-based fibers by uniaxial electrospinning. The effect of flow rate and needle to collector distance on fiber morphology and performance was monitored at $20 \mathrm{kV}$ constant voltage. Fiber diameters, determined by scanning electron microscopy (SEM) varied between $462-833 \mathrm{~nm}$. The drug content of the prepared electrospun fiber mats was monitored by UV spectroscopy and good correlations were found between the obtained and theoretical values. Tracking the changes in solid-state upon electrospinning were carried out by differential scanning calorimetry (DSC). The obtained DSC curves indicated the amorphization of crystalline fluoxetine during fiber formation. The release of the active ingredient happens in a burst manner and after five minutes dissolution of the fluoxetine is complete. The results presented herein could pave the way for a buccal, easy-to-use formulation of the antidepressant drug with greater patient compliance.
\end{abstract}

Keywords: SEM, electrospinning, dissolution, fluoxetine, nanofiber

Fluoxetine (FLU chemical structure on Figure 1, N-methyl-3-phenyl-3-(2,2,2-trifluoro-ptolyloxy) propylamine hydrochloride, is a selective serotonin reuptake inhibitor (SSRI) used in the treatment of depression and obsessive-compulsive disorder. It is generally considered one of the most stimulating representatives of the SSRI class with a mild side-effect profile, making it one of the most prescribed drugs in the world. The main route of administration for the antidepressant is the oral one (1-5) and it is metabolized to the also pharmacologically active norfluoxetine (N-demetyl-fluoxetine), but the biotransformation process shows great inter-individual variability (6-8). Although other therapeutic options are also available, antidepressant medications continue to be the main treatment options for depression. However, one of the major obstacles of antidepressant medication therapy is keeping the patients adhere to the prescribed regimen (9). Both mental (depression and anxiety) and physical health are risk factors associated with therapeutic non-adherence. Improving patient adherence brings positive therapeutic outcomes. Loading active substances to fast dissolving webs enables a customized drug delivery. Ease of administration is a major benefit in formulating fast disintegrating/ dissolving drug delivery systems, along with intake without water and no chewing. Nanofibers with immediate drug release usually present homogenous structures of a drug and polymer mixture. A suitable highly water-soluble polymer incorporates the drug improving solubility and dissolution (10-14).
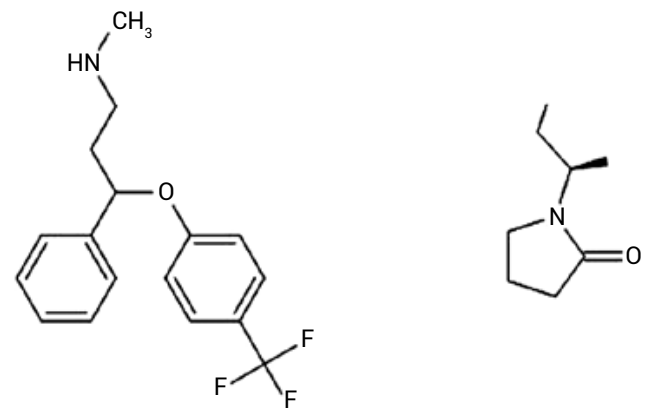

Figure 1. The chemical structures of fluoxetine and PVP

* Corresponding author: e-mail: emoke.redai@umfst.ro 
Hydrophilic polymer-based electrospun nanofibers are created by the elongation of electrified dispersion jets. During the flight, the solvent rapidly evaporates, and the solidified solid dispersion is collected (15). Theoretical and mathematical descriptions of the process of electrospinning can offer further possibilities of prediction and optimization (16).

Popular hydrophilic polymers for electrospinning include hydroxypropyl methylcellulose, alginates, polyvinyl alcohol, polyvinyl pyrrolidone (PVP), sodium carboxymethyl cellulose, dextran. PVP is a chemically stable, biocompatible, synthetic polymer, highly soluble in water and ethanol, which shows an affinity for both hydrophobic and hydrophilic drugs (17). PVP types differ in average molecular weight, degree of polymerization, and viscosity of the obtained solutions (18). It is often used as the fiber-forming polymer in nano- and microfiber-based formulations, especially for its rapid drug release and ability to increase the solubility of the incorporated active substances (19-21). Thus, electrospinning can be a flexible single-step process for producing PVP-based nano- or microfibers from viscous solutions containing the active pharmaceutical ingredient (API) of interest. Although there are several approaches to obtain amorphous solid dispersion (ASD), such as melt extrusion or solvent evaporation, electrospinning offers several advantages. Rapid drying speeds, compatibility with thermolabile APIs and large surface area and porosity, the possibility of fine-tuning drug release by altering processing parameters, and the ability to generally maintain the incorporated API in an amorphous state for a longer time, when compared to other ASD preparation methods $(22,23)$.

Ziaee et al. concluded that, due to their fibrous morphology and high surface area, electrospun amorphous solid dispersions offered higher dissolution rates for ibuprofen, than spray-drying or rotary evaporation (24). Similar observations were also described by Zsombor K. Nagy et al in the case of itraconazole-loaded ASDs (25).

Although several formulations were already described for the buccal administration of FLU, nanofiber-based approaches were yet to be employed (26-27). Thus, given the inherent advantages of electrospinning for the preparation of ASDs, in this study, we describe for the first time, the preparation and evaluation of fast-dissolving FLU-loaded, hydrophilic polymer-based fibrous meshes by uniaxial electrospinning. Electrospinning parameters (flow rate, needle collector distance) were modified for optimization of the method of preparation. Fiber morphology was tracked by SEM studies, while the determination of drug content of fiber mats, dissolution, and solid-state characterization by DSC and FTIR was also aimed. Mathematical models were used for a better understanding of dissolution mechanisms.

\section{EXPERIMENTAL}

Plasdone K-29/32 (Povidone USP), Polyvinyl pyrrolidone K VALUE 29 TO 32 (PVP), was a kind gift of GAF Chemicals (USA), fluoxetine hydrochloride was from Solmag, Italy, while ethanol was purchased from The Chemical Company, Romania. Solvents were of analytical grade.

\section{Preparation of electrospun fibers}

PVP dispersion was obtained at room temperature by dissolving $2 \mathrm{~g}$ PVP in $15 \mathrm{~g}$ ethanol, then $0.3 \mathrm{~g}$ FLU was added under continuous stirring (500 rpm) on a JK SMS HS magnetic stirrer (JKI, Shanghai, China). FLU containing fibrous sheets were prepared with an eSpin Tube system (SpinSplit Hungary) with the following experimental parameters: 10 and $12 \mathrm{~cm}$ needle (inner diameter $0.8 \mathrm{~cm}$ ) collector distance, $20 \mathrm{kV}$ applied voltage, $0.2,0.3,0.4 \mu \mathrm{L} / \mathrm{sec}$ flow rate. We obtained in total six different samples (codified as follows: V210 for fibers obtained at a speed of $0.2 \mu \mathrm{L} / \mathrm{sec}$ at a distance of $10 \mathrm{~cm}, \mathrm{~V} 310$ for fibers obtained at a speed of $0.3 \mu \mathrm{L} / \mathrm{sec}$ at a distance of $10 \mathrm{~cm}$ and so on).

\section{Determination of fiber morphology}

Scanning electron microscopy (SEM) was used to investigate the fiber mat morphology and to determine the average fiber diameters. A JEOL JSM-5200 (JEOL, Tokyo, Japan) scanning electron microscope was utilized at $15 \mathrm{kV}$ and $20 \mathrm{~cm}$ working distance on neat, not sputter-coated, samples. The diameter of 50 randomly selected fibers was measured for each sample using the ImageJ software (version 1.5 US National Institutes of Health, USA).

\section{Determination of API content}

$10 \mathrm{mg}$ of FLU sheets were accurately weighed and dissolved in a $100 \mathrm{~mL}$ volumetric flask in phosphate buffer at a $\mathrm{pH}$ of 6.8. FLU content was determined in UV at a wavelength of $268 \mathrm{~nm}$ (apparatus UV-1800 240V IVDD, SHIMADZU UV-VIS).

\section{Solid-state characterization}

Differential scanning calorimetry was performed by a Shimadzu DSC 60 apparatus, in the 
Table 1. The equations of mathematic models.

\begin{tabular}{|c|c|c|}
\hline No & Mathematic model & Equation \\
\hline 1. & 0 order kinetic & $\mathrm{F}=\mathrm{k}_{0} * \mathrm{t}$ \\
\hline 2. & First-order kinetic & $\mathrm{F}=100 *\left[1-\mathrm{Exp}\left(-\mathrm{k}_{1} * \mathrm{t}\right)\right]$ \\
\hline 3. & Higuchi & $\mathrm{F}=\mathrm{k}_{\mathrm{H}}{ }^{*} \mathrm{t}^{\wedge} 0.5$ \\
\hline 4. & Higuchi with $\mathrm{F}_{0}$ & $\mathrm{~F}=\mathrm{F}_{0}+\mathrm{k}_{\mathrm{H}}{ }^{*} \mathrm{t}^{\wedge} 0.5$ \\
\hline 5. & Korsmeyer-Peppas & $\mathrm{F}=\mathrm{k}_{\mathrm{KP}}{ }^{*} \mathrm{t}^{\wedge} \mathrm{n}$ \\
\hline 6. & Korsmeyer-Peppas with $\mathrm{F}_{0}$ & $\mathrm{~F}=\mathrm{F}_{0}+\mathrm{k}_{\mathrm{KP}}{ }^{*}{ }^{\wedge} \mathrm{n}$ \\
\hline 7. & Hixson-Crowell & $\mathrm{F}=100 *\left[1-\left(1-\mathrm{k}_{\mathrm{HC}}{ }^{*} \mathrm{t}\right)^{\wedge} 3\right]$ \\
\hline
\end{tabular}

$\mathrm{F}=\%$ liberated active substance at time „t”; $\mathrm{F}_{0}=$ dissolved amount at initial stage; $\mathrm{k}=$ release constant; $\mathrm{K}_{\mathrm{H}}=$ Higuchi constant; $\mathrm{K}_{\mathrm{KP}}=$ Korsmeyer-Peppas constant; $\mathrm{n}=$ exponent indicating the diffusional process mechanism; $\alpha=$ scale parameter; $\beta=$ describes the shape of the dissolution curve: the curve is exponential if $\beta=1$; if $\beta>1$ sigmoidal in form of $\mathrm{S}$; if $\beta<1$ parabolic

temperature range of $30-300^{\circ} \mathrm{C}$, with a heating rate of $5^{\circ} \mathrm{C} / \mathrm{min}$ in an air atmosphere. $5 \mathrm{mg}$ accurately weighted samples were sealed in $40 \mu \mathrm{L}$ aluminum pans. As a reference aluminum oxide was used.

The FTIR spectra were collected using a Thermo Nicolet 380 spectrometer (Thermo Electron Corporation, Madison, USA). The scan range was $4000-1000 \mathrm{~cm}^{-1}$ with 32 scans and a resolution of $4 \mathrm{~cm}^{-1}$. The samples were placed on $\mathrm{Zn}$-Se crystal surface. The FTIR measurements were conducted at room temperature $\left(25^{\circ} \mathrm{C}\right)$.

\section{Dissolution studies and mathematical modeling}

Dissolution was performed using an ERWEKA

DT rotating basket apparatus, in $100 \mathrm{~mL}$ of phosphate buffer $\mathrm{pH} 6.8$, a rotation speed of $50 \mathrm{rpm}$, and a temperature of $37 \pm 0.5^{\circ} \mathrm{C}$. After $5,10,15$, 20, 30 minutes, $5 \mathrm{~mL}$ aliquots were removed and replaced with fresh buffer. FLU content was determined using UV spectroscopy with the same apparatus as mentioned above in UV at a wavelength of $268 \mathrm{~nm}$ (apparatus UV-1800 240V IVDD, SHIMADZU UV-VIS).

Mathematical modeling was carried out using the DD Solver add-in program for Microsoft Excel, with the following models: zero and first order, Higuchi, Higuchi with $\mathrm{F}_{0}$, Hixson-Crowel, Korsmeyer Peppas, and Korsmeyer Peppas with $\mathrm{F}_{0}$ (Table 1 presenting the equations).

\section{Statistical analysis}

All analyses were performed in triplicates and expressed as means \pm standard deviation. One-way analysis of variance (ANOVA) was used to determine significant differences between groups. When P-value was lower than 0.05 , the difference was considered statistically significant.

\section{RESULTS AND DISCUSSION}

In order to achieve fast drug release and increased solubility of the API, PVP was selected as a hydrophilic, biocompatible, and non-toxic polymer. It was also successfully applied in some of our previous studies for preparing rapidly dissolving immediate-release fibrous formulations (21). PVP can be successfully electrospun from a wide variety of solvents, including water, alcohols, and also dimethylformamide $(21,22,28)$. Electrospinning from ethanolic PVP-based viscous solutions is a green and cost-effective method for the preparation of ASDs, and since FLU is also soluble in ethanol, this approach was applied for the preparation of the nanofibrous meshes.

To track fiber formation, the prepared, electrospun samples were subjected to SEM analysis. The obtained images at magnifications of 500x, 1000x, or 5000x are presented in Figures 2-4.

All examined fiber diameters were in the nanosized range. Fiber morphology determination reveals fiber diameters of 462-833 nm (Table 2). Results indicate that needle-to-collector distance significantly influences the fiber diameter: at 0.3 , $0.4 \mu \mathrm{L} / \mathrm{sec}$ flow rate, the increase of needle-to-collector distance leads to an increase of fiber diameter $(\mathrm{p}<0.001)$.

Considering the effect of the flow, an increase in the flow rate is associated with increased fiber diameter and bead formation. Flow rates from 0.2 to $0.4 \mu \mathrm{L} / \mathrm{sec}$ did not cause bead formation, probably because during the flight from needle to collector evaporation of the solvent was complete.

Histograms of distributions of fiber diameters are shown in Figure 5. Fiber diameter is asymmetric (skewed towards the left) and with a tail at the 

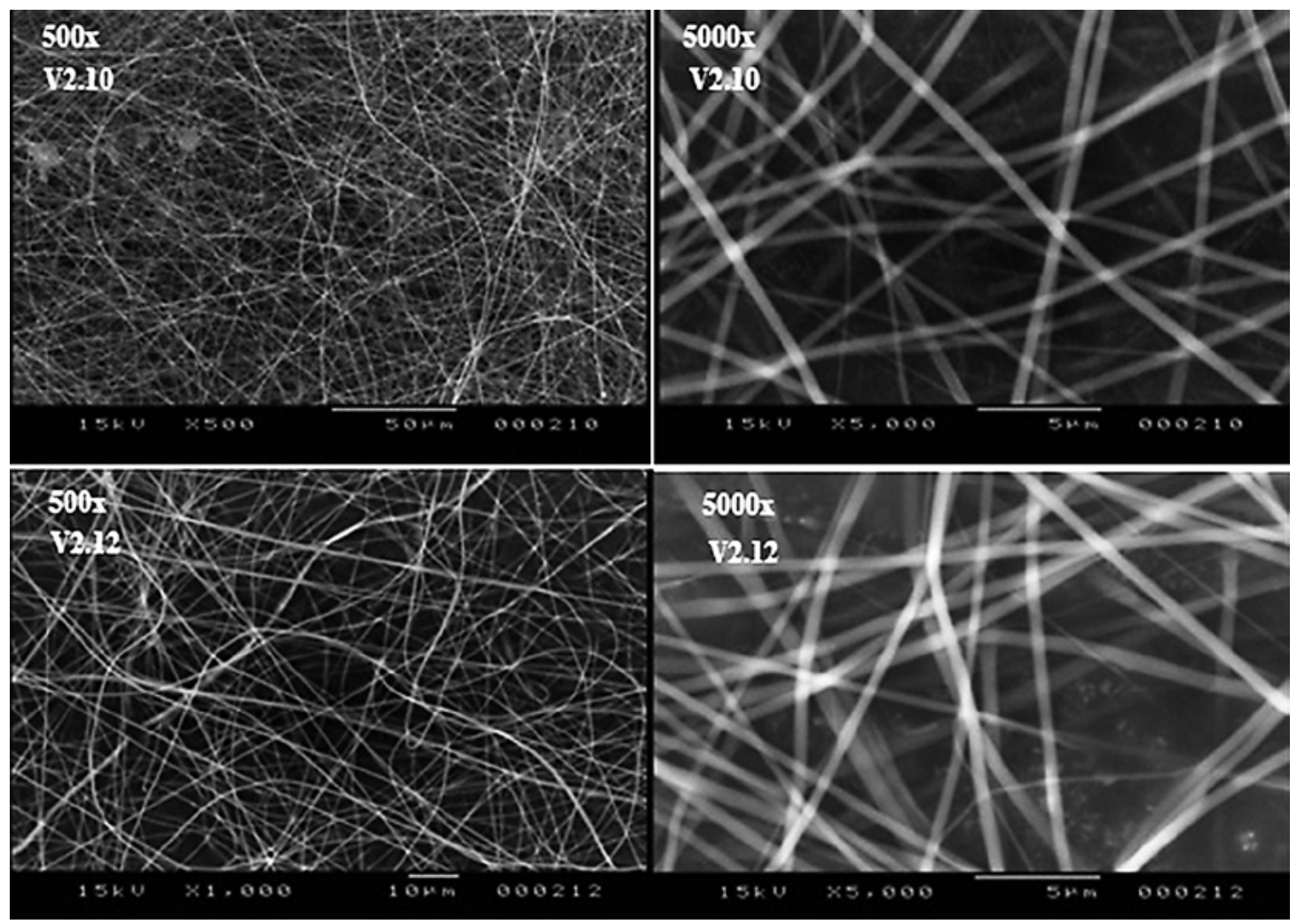

Figure 2. SEM images of V2.10 and V2.12 samples (magnification 500× and 5000×).
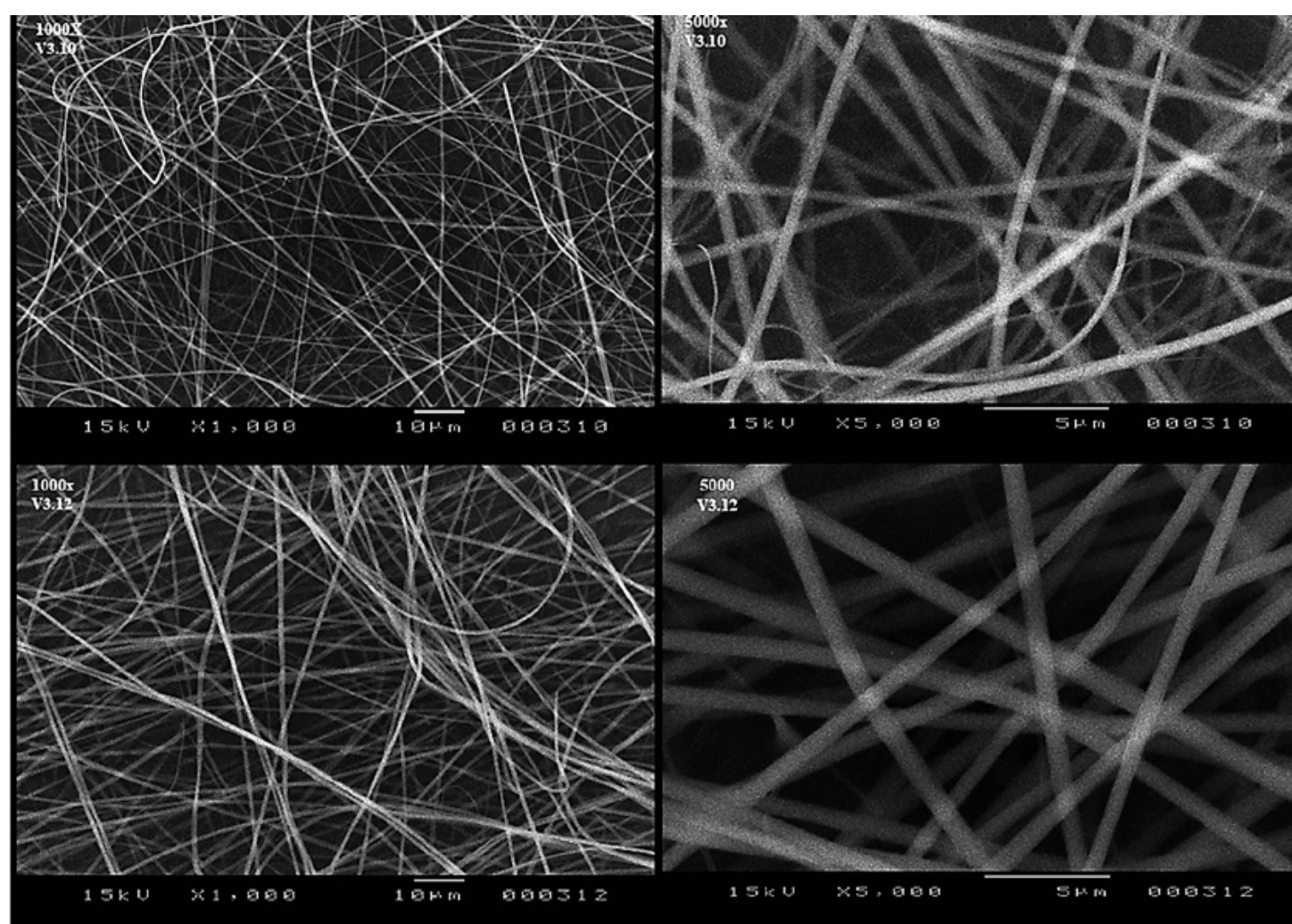

Figure 3. SEM images of V3.10 and V3.12 samples (magnification 500× and 5000×). 


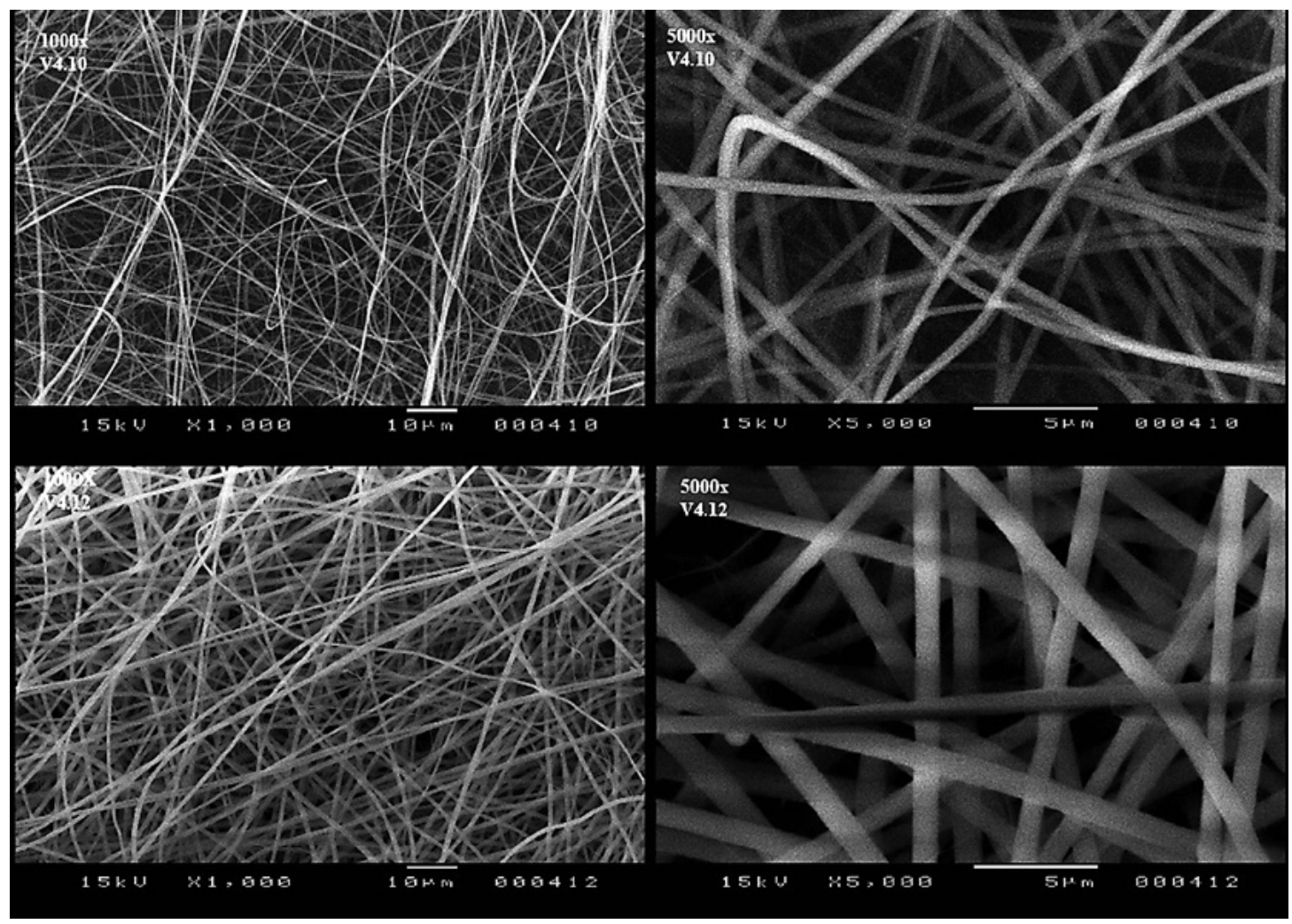

Figure 4. SEM images of V4.10 and V4.12 samples (magnification 500× and 5000×).

Table 2. Fiber diameters and drug content.

\begin{tabular}{|c|c|c|}
\hline Sample & Fiber size $(\mathrm{nm}) \pm \mathrm{SD}$ & FLU content $(\% \mathrm{w} / \mathrm{w}) \pm \mathrm{SD}$ \\
\hline V2.10 & $462 \pm 114$ & $13.45 \pm 1.54$ \\
\hline V2.12 & $493 \pm 129$ & $13.12 \pm 0.55$ \\
\hline V3.10 & $524 \pm 123$ & $14.92 \pm 0.28$ \\
\hline V3.12 & $715 \pm 153$ & $14.08 \pm 0.80$ \\
\hline V4.10 & $494 \pm 117$ & $15.18 \pm 1.63$ \\
\hline V4.12 & $833 \pm 155$ & 183 \\
\hline
\end{tabular}

large diameter end. During flight, the drag force influences fiber size and defines the shape of the distribution.

FLU content of electrospun fibers (Table 2) varies between 13.4 and $15.2 \%(\mathrm{w} / \mathrm{w})$ in a good correlation with the theoretically calculated value of $13 \% \mathrm{w} / \mathrm{w}$. The results reveal that a theoretical dose of $10 \mathrm{mg}$ FLU could be delivered by the administration of $65.8-75.2 \mathrm{mg}$ of electrospun fibrous mesh.

Crystalline FLU is characterized by its melting event displayed as a sharp endothermic peak at $161.38^{\circ} \mathrm{C}$ (Figure 6) comparable to the results obtained in the literature where the endotherm peak occurs between 154 and $\left.161^{\circ} \mathrm{C}\right)(29,30)$. The DSC curve of PVP presents moisture loss as a large endothermic peak, below $100^{\circ} \mathrm{C}$. Thermograms of blank fibers (BF), containing only PVP without the API, are characterized by similar thermal events as the fiber-forming polymer. In the thermograms obtained for the physical mixture (PM, $1: 1$ weight ratio) the thermal events of both FLU (small melting point depression at $160.45^{\circ} \mathrm{C}$ ) and PVP can be distinguished (larger endothermic event below $100^{\circ} \mathrm{C}$, due to moisture loss). In the case of the analyzed fibrous samples (V3.10 and V4.10), only the large endothermic peak of dehydration can be observed, while the endothermic event characteristic for crystalline FLU could not be distinguished, which could suggest an amorphous 

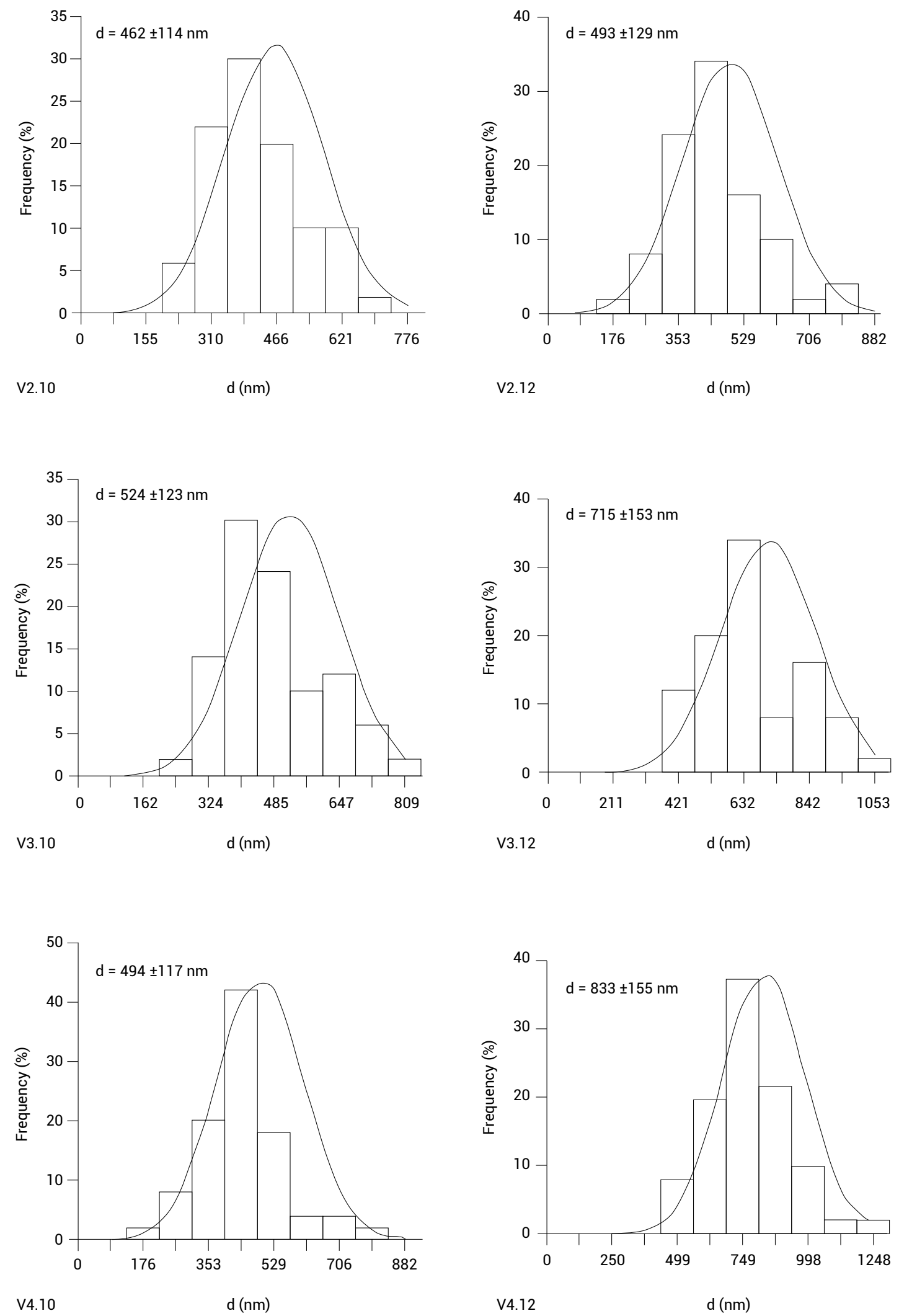

Figure 5. Fiber histograms. 


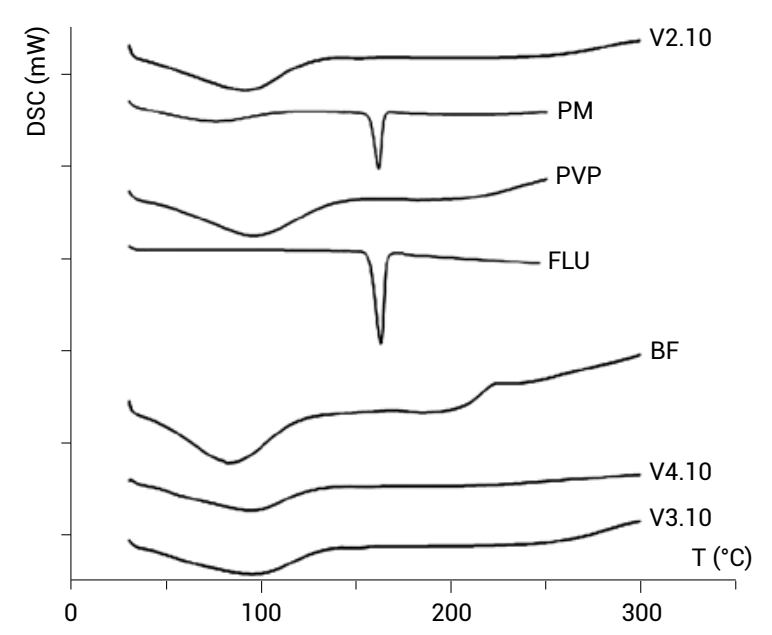

state of the active substance in the obtained fibrous samples.

The IR spectrum of FLU presented characteristic peaks in the region 3000 to $2500 \mathrm{~cm}^{-1}$ vibrations of the amine group and vibrations of aromatic rings. In the wavenumber region from 1700 to $1000 \mathrm{~cm}^{-1}$ bands of the carbon-carbon single bond stretching vibrations in the aromatic ring
Figure 6. Thermograms of FLU, samples, PVP, blank fiber $(\mathrm{BF})$, and physical mixture (PM).

and stretching of the $\mathrm{C}$ - $\mathrm{O}$ and $\mathrm{CF}$ single bond bonds are present (31). Fiber forming PVP shows a marked resonance peak of the carbonyl group (of the pyrrolidine ring) stretching at $1646 \mathrm{~cm}^{-1}$. The spectrum of FLX loaded samples presents the characteristic peak of PVP with a shift to $1652 \mathrm{~cm}^{-1}$, however, the peaks of FLU are not clearly distinguishable (Figure 7).

Dissolution from the fiber mats is fast after 5 minutes almost all FLU being released (Figure 8). In the case of FLU nanofibers, dissolution may be compared to immediate-release pharmaceutical form with no intention of delaying dissolution or absorption of the drug (32). This kind of drug dissolution is a burst manner release of the drug from the polymer (33). Although all formulations conferred similar release profiles for FLU, fiber diameter increase slightly slows the dissolution, and sample V2.10, which presented the thinnest fibers is characterized by the highest dissolved amount of FLU.

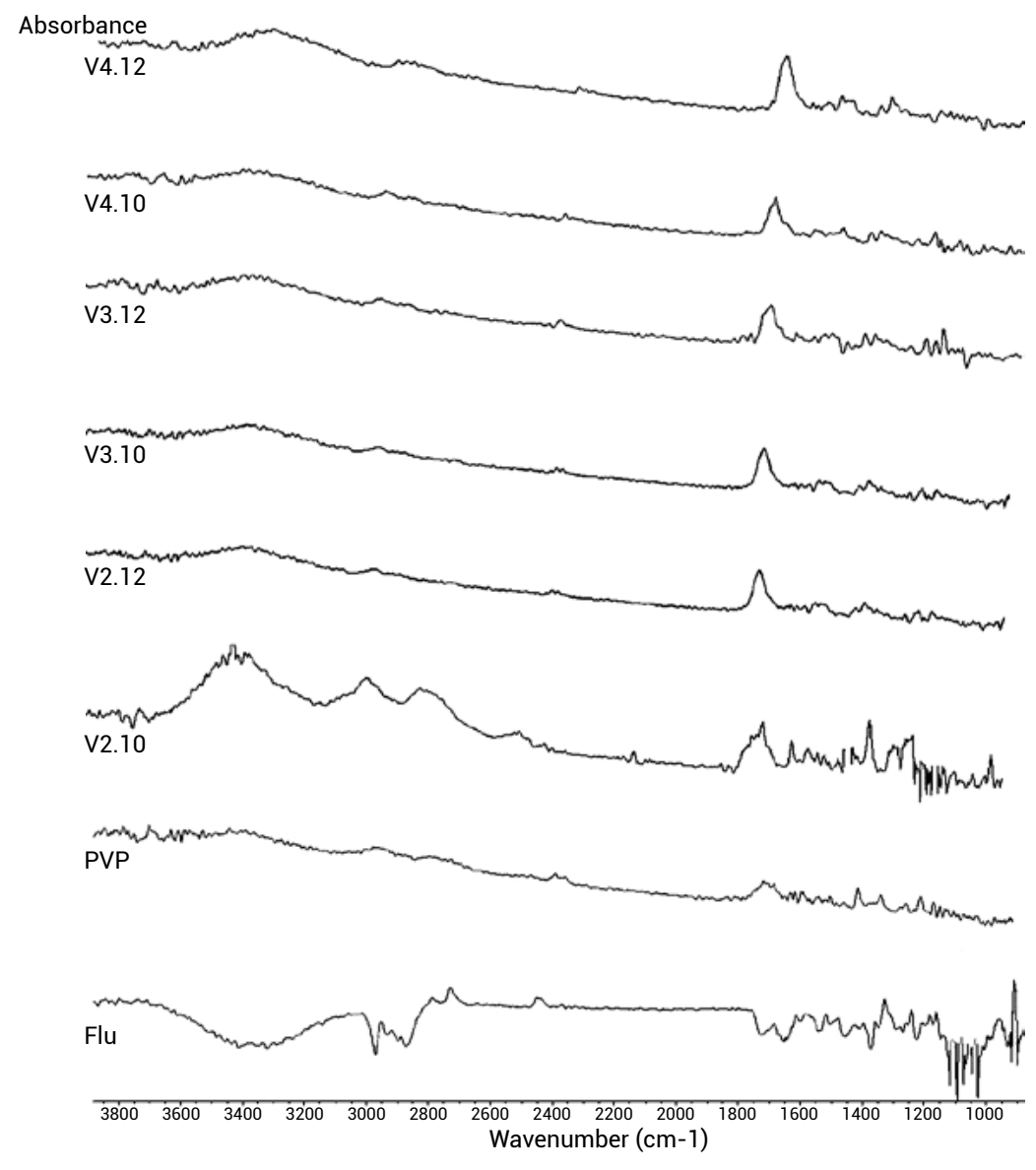

Figure 7. FTIR spectra of FLU, PVP and fibers. 


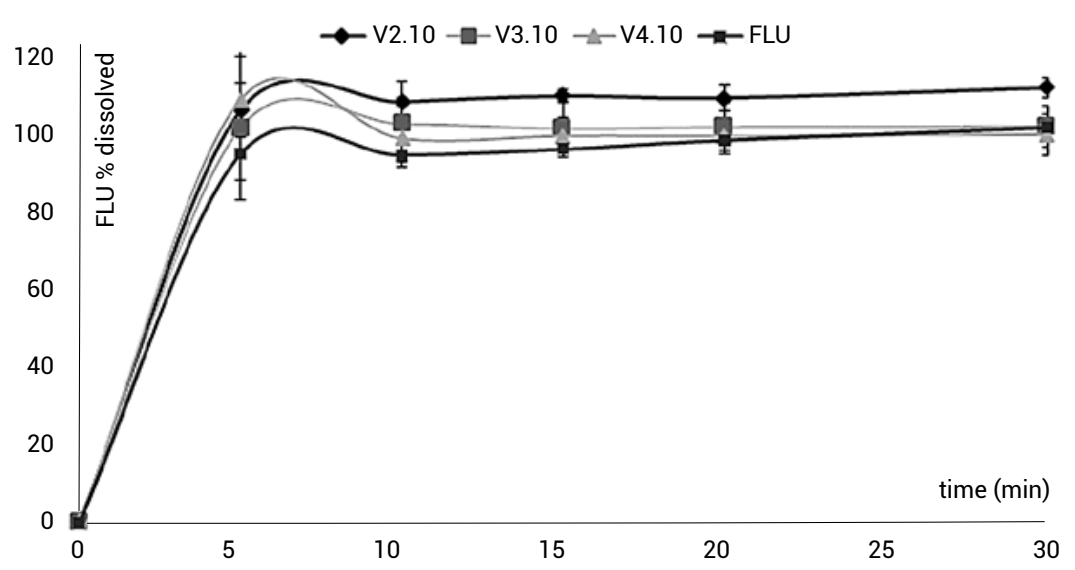

Figure 8. Dissolution curves of FLU and samples.

The release profiles were fitted to five different kinetic models to analyze the in vitro release kinetics. The drug-loaded fibrous webs were considered water-activated release systems, considering a uniform distribution in the fibrous sheets, FLU being simply loaded into a polymeric matrix. AIC - Akaike index is a goodness of fit parameter, lower values indicating better model fitting. The AIC indexes of the models were relatively high above 50, with the exception of the KorsmeyerPeppas model where $\mathrm{n}$ was under 0.5 indicating Fickian diffusion. The high AIC values suggest the need for further elucidation of the release mechanism.

\section{CONCLUSIONS}

A novel, green method was described for the preparation of FLU-containing ASDs. PVP-based FLU containing nanofibers were prepared by uniaxial electrospinning from ethanolic viscous solutions. SEM pictures revealed beadless, smooth filaments and an increase in fiber diameter with an increase in both needle-to-collector distance and flow rate. Based on the results from the solid-state characterization of the obtained fibrous meshes, the API was maintained in an amorphous state. Due to the highly hydrophilic polymer, the high porosity, high surface area of the obtained fibrous samples, and the

Table 3. Parameters of the calculated mathematical models, based on the obtained dissolution data.

\begin{tabular}{|c|c|c|c|c|c|}
\hline No & Mathematical model & Parameter & V2.10 & V3.10 & V4.10 \\
\hline \multirow{2}{*}{1.} & \multirow{2}{*}{0 order kinetic } & $\mathrm{K}_{0}$ & 5.307 & 4.911 & 4.831 \\
\hline & & AIC & 58.55 & 58.11 & 58.54 \\
\hline \multirow{2}{*}{2.} & \multirow{2}{*}{ First-order kinetic } & $\mathrm{K}_{1}$ & - & - & 7.075 \\
\hline & & AIC & & & 27.84 \\
\hline \multirow{2}{*}{3.} & \multirow{2}{*}{ Higuchi } & $\mathrm{K}_{\mathrm{H}}$ & 26.192 & 24.339 & 24.043 \\
\hline & & AIC & 51.75 & 51.65 & 52.63 \\
\hline \multirow{3}{*}{4.} & \multirow{3}{*}{ Higuchi with $\mathrm{F}_{0}$} & $\mathrm{~K}_{\mathrm{H}}$ & 19.406 & 17.610 & 16.766 \\
\hline & & $\mathrm{F}_{0}$ & 28.239 & 28.001 & 30.277 \\
\hline & & AIC & 51.81 & 51.71 & 52.71 \\
\hline \multirow{2}{*}{5.} & \multirow{2}{*}{ Korsmeyer-Peppas } & $\mathrm{K}_{\mathrm{KP}}$ & - & - & 96.348 \\
\hline & & $\mathrm{n}$ & - & - & 0.009 \\
\hline \multirow{4}{*}{6.} & \multirow{4}{*}{$\begin{array}{l}\text { Korsmeyer-Peppas } \\
\text { with } \mathrm{F}_{0}\end{array}$} & $\mathrm{~K}_{\mathrm{KP}}$ & 100.996 & 101.352 & 113.173 \\
\hline & & $\mathrm{n}$ & 0.027 & -0.00017 & -0.0447 \\
\hline & & $\mathrm{F}_{0}$ & 0.000 & - & - \\
\hline & & AIC & 7.27 & & \\
\hline \multirow{2}{*}{7.} & \multirow{2}{*}{ Hixson-Crowell } & $\mathrm{K}_{\mathrm{HC}}$ & - & - & 0.052 \\
\hline & & AIC & & & 49.63 \\
\hline
\end{tabular}


amorphous nature of FLU, the obtained formulations conferred a rapid release of the API, which revealed slightly higher values for samples with lower average fiber diameters. Due to these characteristics and the adequate drug content of the obtained fibers, the electrospun formulation could be a future alternative for rapid oral delivery of FLU to increase the effectiveness of antidepressant therapy.

\section{Conflict of interest}

The authors report no conflicts of interest.

\section{REFERENCES}

1. Tyler C.R., Solomon B.R., Ulibarri A.L., Allan A.M.: Neurtoxicology 44, 98 (2014).

2. Al Asmari A.K., Ullah Z., Al Eid A., Al Kadasah S., Al Sabaan F., Al Shahrani H.:Int. J. Adv. 2, 124 (2014).

3. Roumestan C., Michel A., Bichon F., Portet K., Detoc M., Henriquet C.: Respir. Res. 8, 35 (2007).

4. Hodes G.E., Hill-Smith T.E., Suckow R.F., Cooper T.B., Lucki I.: J. Pharmacol. Exp. Ther. 332, 266 (2010).

5. Lance S., Ternouth I.: N. Z. Med. J. 128, 78 (2015).

6. Llerena A., Dorado P., Berecz R., González A.P., Peñas-Lledó E.M.: Eur. J. Clin. Pharmacol. 59, 869 (2004).

7. Robert A., Schultz I.R., Hucher N., Monsinjon T., Knigge T.: Chemosphere 186, 958 (2017).

8. Dhami K.S., Churchward M.A., Baker GB., Todd K.G.: J. Neurochem. 148, 76 (2019).

9. Zaini S., Sulaiman A.H., Huri H.Z., Hui K., Gill J.S.: Sains Malays. 50, 161 (2021).

10. Reneker D.H., Yarin A.L. Polymer 49, 2387 (2008).

11. Mendez R., Martins S., Fernandez L.: J. Clin. Med. Res. 11, 583 (2019).

12. Baumgartner A., Drame K., Geutjens S., Airaksinen M.: Pharmaceutics 12, 190 (2020).

13. Chevala N.T., Matangi S., Chevala N.P.K., Mahomed G., Seethamraju S.M.K., et al.: J. Pharm. Invest. 45, 493 (2015).
14. Kajdič S., Planinšek O., Gašperlin M., Kocbek P.: J. Drug Deliv. Sci. Technol. 51, 672 (2019).

15. Rafiei S., Maghsoodlou S., Noroozi B., Mottaghitalab V.: Cell. Chem. Technol. 47, 323 (2013).

16. Barhoum A., Bechelany M., Makhlouf A.: Handbook of Nanofibers. 47, Springer International Publishing, Basel 2018.

17. Swei J., Talbot J.B.: J. Appl. Polym. Sci. 90, 1153 (2003).

18. Kurakula M., Rao G.K.: J. Drug Deliv. Sci. Technol. 60, 102046 (2020).

19. Dubey P., Barker S. A., Craig, D.Q.: ACS Omega 5, 1003 (2020).

20. Bolourchian N., TalamkhaniZ., Nokhodchi A.: Pharm. Dev. Technol. 24, 1115 (2019).

21. Sipos E., Kósa N., Kazsoki A., Szabó Z.I., Zelkó R.: Pharmaceutics 11, 417 (2019).

22. Sipos E., Csatári T., Kazsoki A., Gergely A., Bitay E., et al.: Pharmaceutics 12, 612 (2020).

23. Yu D.G., Li J.J., Williams G.R., Zhao M.J.: Control. Release 292, 91 (2018).

24. Ziaee A., O'Dea S., Howard-Hildige A., Padrela L., Potter C., et al.: Int. J. Pharm., 572, 118816 (2019).

25. Nagy Z.K., Balogh A., Démuth B., Pataki H., Vigh T., et al.: Int. J Pharm. 480, 137 (2015).

26. Chevala N.T., Matangi S., Chevala N.P.K., Mohammed G., Seethamraju S.M.K., Nadendla R.R.: J. Pharm Invest. 45, 493 (2015).

27. Rédai E.M., Antonoaea P., Todoran N., Vlad R.A., Bîrsan M., et al.: Processes 9, 778 (2021).

28. Yang Q., Li Z., Hong Y., Zhao Y., Qiu S., et al.: J. Polym. Sci. B Polym. Phys. 42, 3721 (2004).

29. Silva M.A.S., Kelmann R.G., Foppa T., Cruz A.P., Bertol C.D., Sartori T.: J. Therm. Anal. Calorim. 87463 (2007).

30. Pinto BV., Ferreira APG., Cavalheiro E.T.G.: J. Therm. Anal. Calorim. 130, 1553 (2017).

31. Josino M.A.A., Rocha da Silva C., de Andrade Neto J.B., Barroso F.D.D., Juvêncio da Silva L., et al.: Carbohydr. Polym. 252, 117184 (2021).

32. Li X., Kanjwal M.A., Lin L., Chronakis I.S.: Colloids Surf. B Biointerfaces 103, 182, (2013).

33. Costa P., Sousa Lobo J.M. Eur. J. Pharm. Sci. 13, 123 (2001). 